\title{
Prevalence of vitamin D and vitamin B12 deficiency in patients reporting to the West Bank governmental hospitals in the period between January 2015 and December 2018
}

\author{
RESEARCH
}

\section{Bayan Al-Qtishat, Ahmed Al-Jawabreh, and Dina M. Bitar*}

Faculty of Medicine, Al-Quds University, Jerusalem, Palestine

\begin{abstract}
A B S T R A C T
Vitamin D and vitamin B12 deficiencies are major public health problems; they may result from inappropriate low exposure to sunlight, autoimmune diseases or diminished intake. These two deficiencies have been extensively studied globally: causes, effects, treatment, as well as epidemiology. In Palestine the epidemiology of vitamin D and vitamin B12 deficiencies has not been addressed. This study was undertaken to determine the prevalence of vitamin D and vitamin B12 deficiencies in patients reporting to the West Bank (WB) governmental hospitals in the period between January 2015 and December 2018. It is a retrospective cross-sectional study for the data collected from medical records of patients tested for these deficiencies in 12 WB governmental hospitals for the three years period. Out of 30890 patients tested for vitamin D levels, $88 \%$ had insufficient vitamin D levels ( $<30 \mathrm{ng} / \mathrm{ml}$ ), whereas out of 43532 patients tested for vitamin B12, 19\% had insufficient vitamin B12 levels $(<203 \mathrm{pg} / \mathrm{ml})$. The percentage of patients with insufficient vitamin D levels is alarming. The percentage of patients with insufficient vitamin B12 levels falls within ranges reported by other studies in various countries. In conclusion, this study revealed an alarmingly high percentage (88\%) of vitamin D deficiency below the reference sufficiency level among patients suspected to have such a deficiency. Around one fifth of the patients tested for vitamin B12 had insufficient levels. Because testing for vitamin $D$ is costly, we suggest, that medical suspicion of vitamin $D$ deficiency would be adequate to initiate treatment to alleviate the expense, especially in high-risk groups such as elderly women. Future studies have to address major risk factors contributing to these deficiencies that are specific to our community.
\end{abstract}

Keywords: Vitamin D, Vitamin B12, Deficiency, prevalence, West Bank, Palestine.

\section{Introduction}

Vitamin D and vitamin B12 play critical roles in the human body and in its development. Vitamin D was previously associated with calcium absorption and healthy bones only. Nowadays, with more recent studies showing that the vitamin $D$ receptor is present on almost

\footnotetext{
* Correspondance:

Department of Microbiology and Immunology, Faculty of Medicine, Al-Quds University, Jerusalem, Palestine

E-mail: dbitar@staff.alquds.edu / Tel: +972599909975
}

(C) copy rights 2021: All materials in this article is protected, permission requests should be addressed Al-Quds University. www.alquds.edu all cell membranes (Szabó 2011), we understand that it has more sophisticated functions. For example, potent inhibition of cellular growth and renin production, stimulation for insulin release, intrinsic factor production, and immune modulation (Haroon \& Regan, 2010). Vitamin $D$ deficiency leads to a variety of conditions starting with mild muscle pain and weakness to increased risk of osteoporosis or worse yet cancers and autoimmune diseases (Sahota, 2014). Vitamin D3 is obtained from the diet and from sunlight exposure. It is formed in the skin as a result of exposure to UBV radiation between 280 
and $315 \mathrm{~nm}$ wavelengths on 7 dihydrocholestrol, a substance normally found in the skin. It is then converted to 25-hydroxyvitamin D $(25(\mathrm{oH}) \mathrm{D})$ in the liver; the storage form, which is the form used as an indicator for serum vitamin D status. Further metabolism occurs in the kidneys giving the biologically active form 1,25 hydroxyvitamin D (1,25-(OH)D) also known as calcitriol (Sahota 2014). Vitamin B12 functions in myelination of the nerves and long-term maintenance of the nervous system. It also has a major role in red blood cell formation. Vitamin B12 deficiency leads to megaloblastic anemia and combined subacute degeneration of the spinal cord, which manifests as general weakness, tingling or numbness in hands and/or feet and confusion (Oberley \& Yang 2013). Vitamin B12 (cobalamin) cannot be synthesized in the human body and needs to be obtained from the diet such as meat, eggs and dairy products (Green et al., 2017). There are two assays used for measuring $25(\mathrm{OH}) \mathrm{D}$ in the serum. The golden test is by employing chromatography, the other is immunebased assay, which is the most commonly used assay in clinical practice (Sahota 2014). The cutoff point to determine deficiency or insufficiency of vitamin D remains a controversy; different studies use different reference levels.

The Institute of Medicine (IOM) report in 2011 indicated that adequate levels of vitamin $D$ range between $50-125 \mathrm{nmol} / \mathrm{l}(20-50 \mathrm{ng} / \mathrm{ml}$ ) (Ross et al., 2011). In this study, based on the cutoff points by the IOM for vitamin D, levels lower than $75 \mathrm{nmol} / \mathrm{l}$ (30 ng/mL) were considered as insufficient, lower than $50 \mathrm{nmol} / \mathrm{l}(20 \mathrm{ng} / \mathrm{mL})$ as deficiency levels, and higher than $125 \mathrm{nmol} / \mathrm{l}(50 \mathrm{ng} / \mathrm{mL})$ as harmful levels. However, clinical deficiency only shows in levels lower than $25 \mathrm{nmol} / \mathrm{l}(10 \mathrm{ng} / \mathrm{mL})$. To diagnose vitamin B12 deficiency, total serum vitamin B12 concentration is measured. Different cutoff values are used to determine vitamin B12 status. However, according to the WHO, the cutoff value suggested for defining vitamin B12 deficiency is < 203 pg/ml (150 pmol/L) serum vitamin B12. In this study, the normal reference range for serum vitamin B12 will be considered to be between 200 - 900 pg/ml (Hannibal et al., 2017). In Jordan, one-third of the adult population (age $>18$ years) suffer from vitamin B12 deficiency (levels below $200 \mathrm{pg} / \mathrm{ml}$ ) with no difference between males and females (El-Khateeb et al., 2014). Vitamin D and vitamin B12 deficiencies appear to be a pandemic phenomenon, but still not well characterized in Palestine, thus this study is an attempt to provide more insight into the status of these two vitamins in the Palestinian population.

This study aimed to fill the gap between public perception of the extent of this health problem and actual data. Lastly, it is an effort to direct the spotlight on the wealth of data, the Palestinian health care system has and to illustrate how this rich pool of data can be utilized for studies that would altogether give a clear picture of the health status in Palestine.

\section{Materials and methods}

This study is a retrospective cross-sectional study. The data was collected from twelve governmental hospitals' medical records covering the northern, central and southern governorates. The data was kindly provided by the information technology department in the Palestinian ministry of health. The collected data included all vitamin B12 and vitamin $\mathrm{D}$ test results during the period between Jan 2015 to Dec 2018, along with the demographic patients' data including age, gender, and city of residence. The collection was done separately for each vitamin and for each year.

Permission to collect this data was obtained from the health education department, ministry of health (letter number: 162/1881/2018 on 19/11/2018). The total number of data collected for vitamin $D$ and vitamin B12 was 32994 and 48191 respectively. The data was filtered by removing items that did not include all the targeted information; leaving 30890 valid items for vitamin D, and 44916 for vitamin B12. Additional filtering for vitamin B12 data was done by removing the outliers (any test result above $950 \mathrm{pg} / \mathrm{ml}$ or below $50 \mathrm{pg} / \mathrm{ml}$ ). This was necessary because high levels (>950 pg/ml) may indicate assay technical failure, liver disease or occult malignancy etc; while levels below (50 pg/ $\mathrm{ml}$ ) can be seen in pregnancy, folic acid deficiency 
etc. (Oberley \& Yang 2013). The final sample size for Vitamin B12 was accordingly 43532. The details on outliers are provided in Table 1.

Table 1: Vitamin B12 data distribution among

hospitals

\begin{tabular}{ccccc}
\hline Hospital & $\begin{array}{c}\text { Sample } \\
\text { size before } \\
\text { removing } \\
\text { outliers }\end{array}$ & Number of & Percentage of & Sample \\
outliers & $\begin{array}{c}\text { Size after } \\
\text { removing } \\
\text { outliers }\end{array}$ \\
\hline W & 1155 & 51 & $4 \%$ & 1104 \\
BJ & 5612 & 179 & $3 \%$ & 5433 \\
D & 4189 & 89 & $2 \%$ & 4100 \\
H & 12181 & 507 & $4 \%$ & 11674 \\
J & 3485 & 124 & $4 \%$ & 3361 \\
Jr & 3852 & 100 & $3 \%$ & 3752 \\
R & 10321 & 227 & $3 \%$ & 10094 \\
N & 1544 & 45 & $3 \%$ & 1499 \\
S & 384 & 17 & $4 \%$ & 376 \\
T & 887 & 14 & $2 \%$ & 873 \\
TL & 848 & 24 & $3 \%$ & 824 \\
Y & 458 & 16 & $4 \%$ & 442 \\
Total & 44916 & 1393 & - & 43532 \\
\hline & & & & \\
\hline
\end{tabular}

All the data was analyzed using Statistix 2.0

\section{Results}

\section{Vitamin D Results}

The sample size collected from hospitals' records, examined for vitamin D status after filtering was 30890. Females represented $71 \%$ (22060) of the sample with a mean \pm SD of $(16 \mathrm{ng} /$ $\mathrm{ml} \pm 15)$ Vitamin D level, $88 \%$ of which were below normal levels (30-49.9 $\mathrm{ng} / \mathrm{ml})$. Males represented $29 \%$ (8830), with a mean \pm SD Vitamin D level of $(18 \mathrm{ng} / \mathrm{ml} \pm 15.5), 89 \%$ of which were below the normal levels.

Eighty eight percent of all the samples tested had a vitamin D level below normal (30 $\mathrm{ng} / \mathrm{ml}$ ), with the following distribution: $15 \%$ with insufficiency (20-29.9 $\mathrm{ng} / \mathrm{ml}), 31 \%$ with deficiency (10-19.9 $\mathrm{ng} / \mathrm{ml})$ and $42 \%$ with clinical deficiency $(<9.9 \mathrm{ng} / \mathrm{ml})$ as shown in Table 2.

Table 2: Distribution of Vitamin D status ( $\mathrm{ng} / \mathrm{ml}$ )

\begin{tabular}{|c|c|c|c|c|c|c|}
\hline & $\begin{array}{c}\text { Clinical } \\
\text { deficiency } \\
(<9.9 \mathrm{ng} / \mathrm{ml})\end{array}$ & $\begin{array}{c}\text { Deficiency } \\
\text { (10-19.9ng/ } \\
\mathrm{ml})\end{array}$ & $\begin{array}{l}\text { Insufficiency } \\
\text { (20-29.9ng/ml) }\end{array}$ & $\begin{array}{c}\text { Normal } \\
(30-49.9 \\
\mathrm{ng} / \mathrm{ml})\end{array}$ & $\begin{array}{c}\text { High } \\
\text { (>50ng/ } \\
\text { ml) }\end{array}$ & Total \\
\hline $\begin{array}{l}\text { Number of } \\
\text { patients } \\
\text { tested }\end{array}$ & 12867 & 9510 & 4818 & 2900 & 795 & 30890 \\
\hline Percentage & $42 \%$ & $31 \%$ & $15 \%$ & $9 \%$ & $3 \%$ & $100 \%$ \\
\hline $\begin{array}{l}\text { Mean of } \\
\text { vitamin D } \\
\mathrm{ng} / \mathrm{ml}\end{array}$ & 7 & 14 & 24 & 37 & 71 & 16 \\
\hline $\begin{array}{l}\text { Std. } \\
\text { Deviation }\end{array}$ & 2 & 3 & 3 & 5 & 60 & 16 \\
\hline
\end{tabular}

Table 3: Vitamin D status $(\mathrm{ng} / \mathrm{ml})$ trend within years (2015-2018)

\begin{tabular}{lcccc}
\hline Year & 2015 & 2016 & 2017 & 2018 \\
\hline Number of patients & 387 & 4705 & 11972 & 13862 \\
tested & & & & \\
Mean of vitamin D ng/ml & 16 & 15 & 16 & 17 \\
Std. Deviation & 11 & 13 & 15 & 19 \\
\hline
\end{tabular}


As shown in Table 3, the number of patients who were tested for vitamin $D$ deficiency increased from 387 in 2015 to 13862 in 2018 which represents 35.8x fold, with an insignificant improvement in vitamin D deficiency from a mean \pm SD of (16 ng/ $\mathrm{ml} \pm 11)$ in 2015 to $(17 \mathrm{ng} / \mathrm{ml} \pm 19)$ in 2018 .

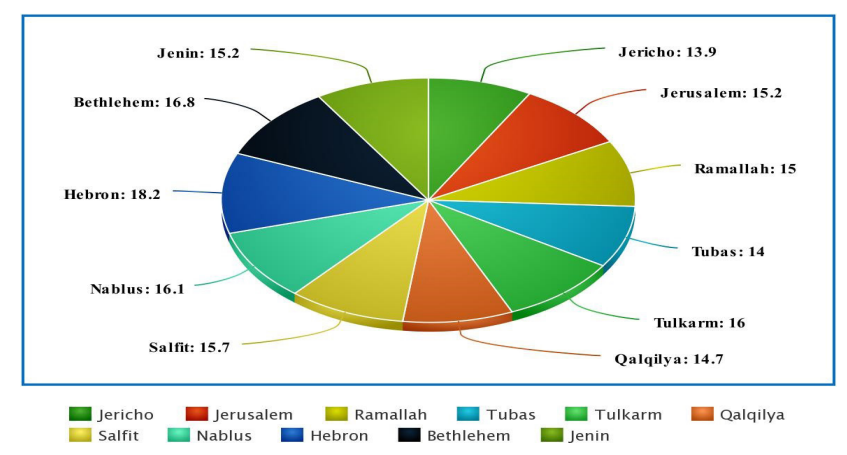

Figure 1: Vitamin D status $(\mathrm{ng} / \mathrm{ml})$ trend within WB cities

Further description of the vitamin D status (ng/ $\mathrm{ml}$ ) according to the city and the age of the patients tested are shown in Figures 1 and 2 respectively.

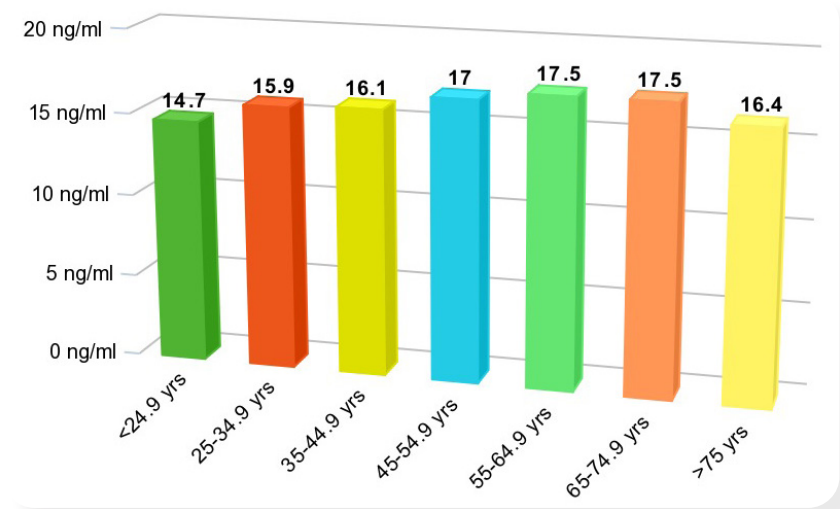

Figure 2: Vitamin D status $(\mathrm{ng} / \mathrm{ml})$ trend within age groups

Vitamin D status ( $\mathrm{ng} / \mathrm{ml}$ ) mean in all age groups was less than $(20 \mathrm{ng} / \mathrm{ml})$ indicating deficiency, with no significant difference as referred to the patient's city origin.

\section{Vitamin B12}

The number of patients examined for vitamin B12 deficiency and included in this investigation was 43534. Females represented 66 $\%$ (28769) with a mean of vitamin B12 level pg/ml $\pm \mathrm{SD}$, $(335 \mathrm{pg} / \mathrm{ml} \pm 161), 18.6 \%$ of the females with deficiency levels, while males represented $34 \%$ (14763) with a mean of vitamin B12 level pg/ml \pm SD, $(328 \mathrm{pg} / \mathrm{ml} \pm 161)$ with $19.7 \%$ with a deficiency level. Out of the total (43534) tested for vitamin B12 levels, 158 (19\%) had B12 deficiency (<199.9 pg/ $\mathrm{ml})$ as shown in Table 4.

Table 4: The distribution of vitamin B12 level ( $\mathrm{pg} / \mathrm{ml})$

\begin{tabular}{lcccc}
\hline & Deficient & Normal & High & Total \\
\hline & $(<199.9$ & $(200-899.9$ & $(>900$ & \\
& $\mathrm{pg} / \mathrm{ml})$ & $\mathrm{pg} / \mathrm{ml})$ & $\mathrm{pg} / \mathrm{ml})$ & \\
& 8265 & 35050 & 219 & 43534 \\
$\begin{array}{l}\text { Number of } \\
\text { patients } \\
\text { tested }\end{array}$ & & & & \\
$\begin{array}{l}\text { Mean of } \\
\text { vitamin B12 } \\
\text { pg/ml }\end{array}$ & 158 & 370 & 924 & 434 \\
$\begin{array}{l}\text { Std. } \\
\text { Deviation }\end{array}$ & 30 & 145 & 15 & 63.3 \\
\hline $\begin{array}{l}\text { Percentage } \\
\text { (19\% }\end{array}$ & $80.5 \%$ & $0.5 \%$ & $100 \%$
\end{tabular}

Table 5: Vitamin B12 levels $(\mathrm{pg} / \mathrm{ml})$ trend within years (2015-2018)

\begin{tabular}{lcccc}
\hline Year & 2015 & 2016 & 2017 & 2018 \\
\hline $\begin{array}{l}\text { Number of } \\
\text { patients }\end{array}$ & 4789 & 9751 & 12435 & 16559 \\
tested & & & & \\
Mean of & 341 & 319 & 334 & 338 \\
vitamin B12 & & & & \\
pg/ml & & & & \\
Std. Deviation & 160 & 156 & 161 & 163 \\
\hline
\end{tabular}

As shown in Table 5, the number of patients tested for vitamin B12 serum level increased from 4789 in 2015 to 16559 in 2018 representing a 3.5x fold. Further description of the vitamin B12 mean according to the city and the age of the patients tested are shown in Figures 3 and 4 respectively. 


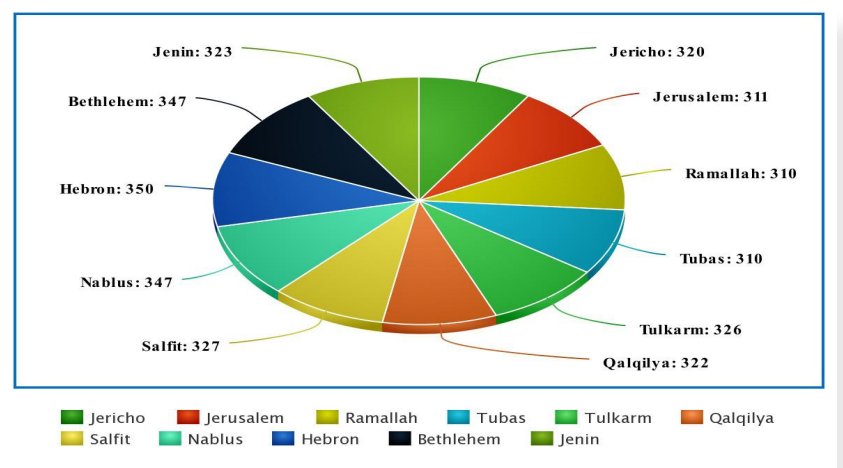

Figure 3: Vitamin B12 level $(\mathrm{pg} / \mathrm{ml})$ trend within WB cities

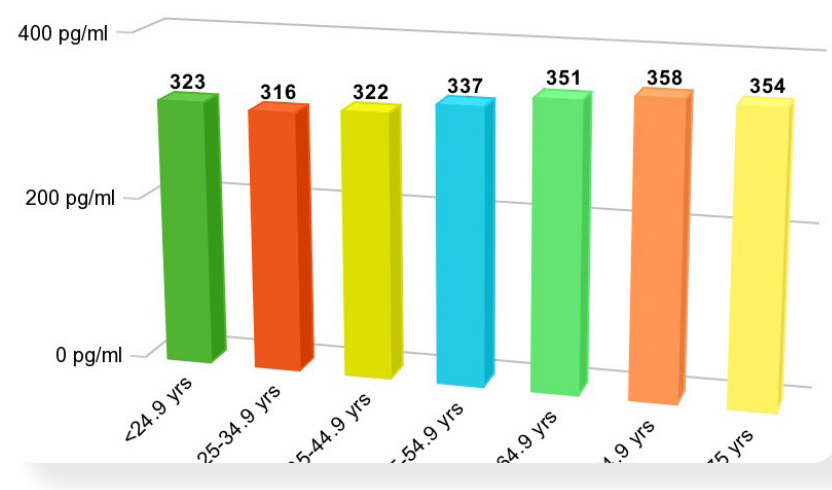

Figure 4: Vitamin B12 level $(\mathrm{pg} / \mathrm{ml})$ within age groups

Vitamin B12 mean levels (pg/ml) for all patients examined between January 2015 and December 2018 were within the normal range (Figure 3) and the same is true when the vitamin B12 levels in the patients from the different cities (Figure 4) were compared.

\section{Discussion}

This study shows the extent of vitamin $D$ and Vitamin B12 deficiencies in patients reporting to the West Bank governmental hospitals in the state of Palestine during the period 2015 - 2018. The number of females examined for vitamin D deficiency was $2.4 x$ fold greater than the number of males examined. The prevalence of deficiency between these two groups was similar, 88\% below normal levels for the females and $89 \%$ below normal levels for the males. The mean level for vitamin $\mathrm{D}$ testing is $(16 \mathrm{ng} / \mathrm{ml} \pm 15)$, with $73 \%$ of the sample below the deficiency levels (10-19.9 $\mathrm{ng} / \mathrm{ml}$ ) and $88 \%$ below the sufficient levels (30-50 $\mathrm{ng} / \mathrm{ml}$ ). Previous studies on two subpopulations in Palestine similarly showed a high prevalence rate of vitamin D deficiency, in which $60.7 \%$ of the children were vitamin D deficient (Chaudhry, Hajat \& Rizkallah, 2018). While the deficiency prevalence was $85.9 \%$ in postmenopausal women (Kharroubi, Saba, Smoom, Bader, \& Darwish, 2017).

The prevalence of vitamin $D$ deficiency in the neighboring countries is similarly high. In Syria, the prevalence of vitamin D deficiency is 61\% (SayedHassan, Abazid, \& Alourfi, 2014), while in Jordan it is 60.3\%(Nichols et al., 2012) and Saudi Arabia is 52.6\% (Ardawi, Sibiany, Bakhsh, Qari, \& Maimani, 2012). The overall vitamin $D$ deficiency prevalence in the Middle East in a systematic review was found to be between $30-90 \%$ depending on the type of study, country, age etc (Bassil, Rahme, Hoteit, \& Fuleihan, 2013).

In this current study, in the period between 2015 and 2018 there was a remarkable increase (35.8x) in the number of patients tested for vitamin D levels. However, there was a small increase in the mean of vitamin D (Table 3). This slight increase may be due to increased public awareness of vitamin $D$ deficiency and the increased use of vitamin D supplements; as noted by different studies showing the increased use of supplements in different subgroups (Lips et al., 2019). However, other studies still point out that vitamin D supplements' use in the Middle East is not sufficient enough to fulfill the daily requirements of vitamin D (Hwalla et al., 2017).

Use of Vitamin D supplements without testing: where do we stand? In a recent study dedicated to understand the current situation of vitamin $D$ deficiency and means of its prevention in Europe and the Middle East; it was evident that the daily intake of vitamin $D$ in the Middle East is not sufficient enough to meet the required daily dose 
of the vitamin. This same study recommended the use of vitamin D supplements in specific high risk populations including: children younger than the age of 1 year, pregnant women, persons living in institutions, persons older than the age of 70 and all non-Western immigrants (Lips et al., 2019). In the Netherlands, new vitamin D supplementation recommendations state that even adults with dark skin, or white skin adult but insufficient skin exposure should be taking vitamin D supplements (Weggemans, Kromhout, \& Van Weel, 2013.

Two Middle Eastern countries; Saudi Arabia andUnitedArabEmirateshavesetrecommendations for daily vitamin D supplementation taking into consideration the age and the reproductive status of the individual (Al-Daghri et al., 2017; Haq, Wimalawansa, Pludowski, \& Al Anouti, 2018). However, the level of vitamin D supplement use in the Middle East is still low (Hwalla et al., 2017). In Palestine, the ministry of health recommends vitamin D supplementations for children from the age of 21 days until the age of 1 year. In spite of these recommendations, the prevalence of vitamin $\mathrm{D}$ deficiency in children as previously mentioned is 60.7\% (Chaudhry et al., 2018). Recent studies have linked a genetic component to vitamin D concentration worldwide (Shea et al., 2009; Trummer et al., 2012). Some of the heritable polymorphisms linked to vitamin D deficiency level were evaluated in Saudi Arabia and further confirmed the link of two of them to vitamin $D$ deficiency (Sadat-Ali, Al-Turki, Azam, \& Al-Elq, 2016).

In the light of the aforementioned studies and recommendations, and also given the high cost for vitamin D testing in Palestine; the use of vitamin $\mathrm{D}$ supplementation without testing may be recommended for patients who are considered high-risk groups or patients with high clinical suspicion for vitamin D deficiency. Moreover, the risk of vitamin $D$ excess intake is low (Flynn et al., 2009). Most of the cases of vitamin D toxicity are related to errors in fortification of food or formulation of supplements specifically when unlicensed supplements are used (Taylor \& Davies, 2018). With the appropriate prescription and accurate explanation of supplement ingestion this problem can be avoided. Giving supplementation in the aforementioned subgroups of patients without testing might save the government and the individuals the expense of testing; which can be directed toward more comprehensive studies to evaluate the exact prevalence in the general population.

\section{Vitamin $B 12$ in comparison to vitamin D}

The number of females tested for vitamin B deficiency was $1.9 x$ fold greater than the number of males tested, however both groups showed similar deficiency prevalence; $18.6 \%$ for the females and $19.7 \%$ for the males. According to a recent review about vitamin B12 deficiency, asymptomatic vitamin B12 deficiency ranges between 2.5\% to 26\% (Green et al., 2017).

In this study, 19\% exhibited vitamin B12 deficiency, which falls within the general population range. The number of patients tested for vitamin B12 was larger than those tested for vitamin D. This surprising difference in deficiency levels of vitamin B12 and vitamin D is not unique and has been observed before (Yazici et al., 2019). However, it further emphasizes the need for more studies in this area for better understanding and improved management of these health problems. Highly noticeable for vitamin B12 results is the fact that the unfiltered data had abnormally high levels (above $2000 \mathrm{pg} / \mathrm{ml}$ ) for vitamin B12, which may be an indication of lab error(s) or typing error(s) (Oberley \& Yang, 2013); this may be due to several reasons including; under qualified lab workers, heavy workload on the laboratory technicians, or simply faulty equipment. This can be supported by the fact that the percentage of outliers was higher in certain hospitals more 
than the others (Table 1).

This study is a description of the current governmental hospital data; and does not take into account factors such as disease state, dietary habits, or the use of vitamin D or B12 supplements at the time of the test etc. Furthermore, a reconsideration for testing patients prior to giving supplements of vitamin D, especially for the subpopulations with the highest risk such as elderly women, in consideration with the current difficult financial status of the Palestinians in general.

\section{References}

Al-Daghri, N. M., Al-Saleh, Y., Aljohani, N., Sulimani, R., Al-Othman, A. M., Alfawaz, H., ... Alharbi, M. (2017). Vitamin D status correction in Saudi Arabia: an experts' consensus under the auspices of the European Society for Clinical and Economic Aspects of Osteoporosis, Osteoarthritis, and Musculoskeletal Diseases (ESCEO). Archives of Osteoporosis, 12(1), 1.

Ardawi, M.-S., Sibiany, A., Bakhsh, T., Qari, M., \& Maimani, A. (2012). High prevalence of vitamin D deficiency among healthy Saudi Arabian men: relationship to bone mineral density, parathyroid hormone, bone turnover markers, and lifestyle factors. Osteoporosis International, 23(2), 675-686.

Bassil, D., Rahme, M., Hoteit, M., \& Fuleihan, G. E.-H. (2013). Hypovitaminosis D in the Middle East and North Africa: prevalence, risk factors and impact on outcomes. Dermato-endocrinology, 5(2), 274298.

Chaudhry, A. B., Hajat, S., \& Rizkallah, N. (2018). Risk factors for vitamin $A$ and $D$ deficiencies among children under-five in the state of Palestine. Conflict and health, 12(1), 13.

El-Khateeb, M., Khader, Y., Batieha, A., Jaddou, H., Hyassat, D., Belbisi, A., \& Ajlouni, K. (2014). Vitamin B12 deficiency in Jordan: a populationbased study. Ann Nutr Metab, 64(2), 101-105. doi:10.1159/000355440

Flynn, A., Hirvonen, T., Mensink, G. B., Ocké, M. C., Serra-Majem, L., Stos, K., ... Fletcher, R. (2009). Intake of selected nutrients from foods, from fortification and from supplements in various European countries. Food \& Nutrition Research,
53(1), 2038.

Green, R., Allen, L. H., Bjorke-Monsen, A. L., Brito, A., Gueant, J. L., Miller, J. W., . . Yajnik, C. (2017). Vitamin B12 deficiency. Nat Rev Dis Primers, 3, 17040. doi:10.1038/nrdp.2017.40

Hannibal, L., Lysne, V., Bjorke-Monsen, A. L., Behringer, S., Grunert, S. C., Spiekerkoetter, U.,Blom, H. J. (2017). Corrigendum: Biomarkers and Algorithms for the Diagnosis of Vitamin B12 Deficiency. Front Mol Biosci, 4, 53. doi:10.3389/fmolb.2017.00053

Haq, A., Wimalawansa, S. J., Pludowski, P., \& Al Anouti, F. (2018). Clinical practice guidelines for vitamin $D$ in the United Arab Emirates. The Journal of steroid biochemistry and molecular biology, 175, $4-$

Haroon, M., \& Regan, M. J. (2010). Vitamin D deficiency: the time to ignore it has passed. International journal of rheumatic diseases, 13(4), 318-323.

Hwalla, N., Al Dhaheri, A. S., Radwan, H., Alfawaz, H. A., Fouda, M. A., Al-Daghri, N. M., ... Blumberg, J. B. (2017). The prevalence of micronutrient deficiencies and inadequacies in the Middle East and approaches to interventions. Nutrients, 9(3), 229.

Kharroubi, A., Saba, E., Smoom, R., Bader, K., \& Darwish, H. (2017). Serum 25-hydroxyvitamin D and bone turnover markers in Palestinian postmenopausal osteoporosis and normal women. Archives of Osteoporosis, 12(1), 13.

Lips, P., Cashman, K. D., Lamberg-Allardt, C., Bischoff-Ferrari, H. A., Obermayer-Pietsch, B., Bianchi, M. L.,Bouillon, R. (2019). Current vitamin D status in European and Middle East countries and strategies to prevent vitamin $D$ deficiency: a position statement of the European Calcified Tissue Society. European Journal of Endocrinology, 180(4), P23-P54.

Nichols, E., Khatib, I., Aburto, N., Sullivan, K., Scanlon, K., Wirth, J., \& Serdula, M. (2012). Vitamin D status and determinants of deficiency among non-pregnant Jordanian women of reproductive age. European journal of clinical nutrition, 66(6), 751-756.

Oberley, M. J., \& Yang, D. T. (2013). Laboratory testing for cobalamin deficiency in megaloblastic anemia. American journal of hematology, 88(6), 522-526.

Ross, A. C., Manson, J. E., Abrams, S. A., Aloia, J. F., Brannon, P. M., Clinton, S. K., ... Jones, G. (2011). The 2011 report on dietary reference intakes for calcium and vitamin D from the Institute of Medicine: what clinicians need to know. The Journal of Clinical Endocrinology \& Metabolism, 96(1), 53-58.

Sadat-Ali, M., Al-Turki, H. A., Azam, M. Q., \& Al-Elq, A. H. 
(2016). Genetic influence on circulating vitamin D among Saudi Arabians. Saudi medical journal, 37(9), 996.

Sahota, O. (2014). Understanding vitamin D deficiency. Age and ageing, 43(5), 589.

Sayed-Hassan, R., Abazid, N., \& Alourfi, Z. (2014). Relationship between 25-hydroxyvitamin D concentrations, serum calcium, and parathyroid hormone in apparently healthy Syrian people. Archives of Osteoporosis, 9(1), 176.

Shea, M., Benjamin, E., Dupuis, J., Massaro, J., Jacques, P., D'agostino, R., . . . Vasan, R. (2009). Genetic and non-genetic correlates of vitamins $K$ and $D$. European journal of clinical nutrition, 63(4), 458464.

Szabó, A. (2011). Skeletal and extra-skeletal consequences of vitamin $\mathrm{D}$ deficiency. Orvosi hetilap, 152(33), 1312-1319.
Taylor, P. N., \& Davies, J. S. (2018). A review of the growing risk of vitamin $D$ toxicity from inappropriate practice. British journal of clinical pharmacology, 84(6), 1121-1127.

Trummer, O., Schwetz, V., Walter-Finell, D., Lerchbaum, E., Renner, W., Gugatschka, M., . . . ObermayerPietsch, B. (2012). Allelic determinants of vitamin $d$ insufficiency, bone mineral density, and bone fractures. The Journal of Clinical Endocrinology \& Metabolism, 97(7), E1234-E1240.

Weggemans, R., Kromhout, D., \& Van Weel, C. (2013). New dietary reference values for vitamin $D$ in the Netherlands. European journal of clinical nutrition, 67(6), 685-685.

Yazici, A. B., Ciner, O. A., Yazici, E., Cilli, A. S., Dogan, B., \& Erol, A. (2019). Comparison of vitamin B12, vitamin $D$ and folic acid blood levels in patients with schizophrenia, drug addiction and controls. Journal of Clinical Neuroscience, 65, 11-16. 